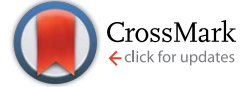

Cite this: RSC Adv., 2017, 7, 5583

Received 13th October 2016 Accepted 25th November 2016

DOI: $10.1039 / c 6 r a 25154 d$

www.rsc.org/advances

\section{Corrosion of carbon steel induced by a microbial- enhanced oil recovery bacterium Pseudomonas sp. SWP-4}

\author{
Guihong Lan, ${ }^{\star a b}$ Chao Chen, ${ }^{\mathrm{b}}$ Yongqiang Liu, ${ }^{\mathrm{c}}$ Yinchun Lu, ${ }^{\mathrm{b}} \mathrm{Jiao}^{\mathrm{Du}}{ }^{\mathrm{b}}$ Sha Tao ${ }^{\mathrm{b}}$ \\ and Shihong Zhang ${ }^{\mathrm{b}}$
}

Pseudomonas sp. SWP-4 has been proved to enhance oil recovery effectively. However, corrosion to oil wells or pipes needs to be evaluated when SWP-4 is used. This study investigated the corrosion behavior of carbon steel induced by SWP-4. Results indicated that a mild effect on corrosion occurred in medium with SWP-4. Electrochemical parameters $\left(E_{\text {corr }}, I_{\text {corr, }}\right.$ and $\left.R_{\mathrm{ct}}\right)$ suggested that SWP-4 promoted the corrosion in the exponential phase in the fastest growth time. Surface morphologies and corrosion products were detected by using scanning electron microscopy and energy dispersive X-ray spectroscopy. Moreover, this study proved that oil-cell-free fermentation broth could inhibit the corrosion and the growth of sulphate-reducing bacteria and saprophytic bacteria.

\section{Introduction}

Microbial Enhanced Oil Recovery (MEOR) methods, making use of microbial activities and metabolic byproducts to decrease the viscosity and to improve the fluidity of crude oil, ${ }^{1}$ have been investigated successfully in laboratory and field conditions, especially in low temperature oilfield reservoirs..$^{2-5}$ Genus Pseudomonas as a high-efficiency crude oil degrader degrading $n$ alkanes ${ }^{6,7}$ and producing rhamnolipid to reduce surface tension both have been considered to be used in the MEOR process. ${ }^{8}$

Microbiologically influenced corrosion (MIC) is of considerable concerns in the oil, gas and marine industries, which results in high corrosion costs. MIC happens due to the bacteria activity and bacterial metabolites in the oil field's water injection systems. To date, most of the studies about Pseudomonas species in the corrosion process of mild steel, stainless steel and aluminum alloys were involved in marine environments. These Pseudomonas strains have also been demonstrated to accelerate and lead to the occurrence of the corrosion of metals and stainless steels. ${ }^{11-16}$ For instance, Franklin et al. ${ }^{11}$ found that Pseudomonas sp. attached on the carbon steel surface may inhibit repassivation which could make pits continue to grow. Hamzah et $a l^{12}$ and Morales et al. ${ }^{13}$ found that microbial

${ }^{a}$ Key Laboratory of Oil \& Gas Applied Chemistry of Sichuan Province, Southwest Petroleum University, No. 8 Xindu Avenue, Xindu District, Chengdu 610500, PR China. E-mail: guihonglan416@sina.com; Fax: +86 02883037306; Tel: +86 02883037306

${ }^{b}$ College of Chemistry and Chemical Engineering, Southwest Petroleum University, Chengdu 610500, PR China

${ }^{c}$ Faculty of Engineering and the Environment, University of Southampton, Southampton SO17 1BJ, UK deposits could induce the occurrence of pitting corrosion and metabolites production may thin the external passive film layer during the presence of Pseudomonas aeruginosa. Moradi et al. ${ }^{14}$ suggested that the adhesion of Pseudomonas sp. and the biofilm with $\mathrm{Cl}, \mathrm{K}$ and $\mathrm{Na}$ could induce localized corrosion of 2205 duplex stainless steel. Pedersen et al. ${ }^{15}$ suggested that Pseudomonas sp. promoted passivity breakdown by excreting organic acids resulting in an increase in the corrosion rate of metals. Busalmen et al. ${ }^{16}$ manifested that the enhancement in corrosion rate was due to the cathodic reduction by the catalase excreted by the genus Pseudomonas. In addition, Beech et al. demonstrated that the metal cations binding by extra-cellular polymeric substances (EPS) could facilitate the ionization of AISI 316 stainless steel surface, thus resulting in thinning the protective layers and changing the electrochemical nature of the metal surface. ${ }^{17-19}$ In recent years, the metal ion chelating properties of bacterial EPS have been considered as an important role in microbiologically influenced corrosion (MIC) of metals. ${ }^{20,21}$ Several investigations have been carried out to verify the corrosive effect of EPS on metal. ${ }^{21,22}$ The nature of the composition of EPS excreted by bacteria has been extensively investigated to determine which functional groups caused the acceleration of corrosion. ${ }^{15,17,19-21,23}$

To inhibit corrosion, a large amount of works have been investigated in the adsorption of chemical surfactants. For the past few years, biosurfactants were also investigated as environment-friendly corrosion inhibitors to pre-treatment the surface of steel..$^{24,25}$ However, surface-active compounds had not been elaborated further in these literatures.

Sulphate-reducing bacteria (SRB) as the prominent groups of microorganisms causing corrosion of steels and stainless steels have been extensively investigated. ${ }^{26-29}$ Biocide has widely been 
used to control the corrosion of different metals and alloys by microorganisms. Additionally, rhamnolipid as a promising biosurfactant has been investigated to have the antibacterial capability in the areas of food and healthcare. ${ }^{30-34}$ Its surfaceactive compound has also been tested for very good antiadhesive properties to prevent contamination of stainless steel surfaces by different pathogenic bacteria. ${ }^{31}$ However, there is hardly a literature reporting about the effects of environmental biosurfactant (rhamnolipid) on the most harmful bacteria corroding the steel on oilfield such as sulphatereducing bacteria (SRB) and saprophytic bacteria (TGB).

In the previous study, ${ }^{9}$ we isolated a strain Pseudomonas sp. SWP-4 which was able to degrade waste cooking oil (WCO) to produce rhamnolipid with low critical micelle concentration and high surface activities. Moreover, we have found that the addition of WCO had positive effects on heavy crude oil degradation and MEOR process. ${ }^{\mathbf{1 0}}$ The MEOR treatments are always conducted through injecting bacteria and nutrients with the normal water flooding operation or fermentation broth to enhance additional oil recovery. To apply Pseudomonas sp. SWP4 in the process further, it is necessary to study the corrosivity of the bacteria towards materials used in seawater injection systems. The present study aims to gain a further understanding on the influence of Pseudomonas sp. SWP-4 and the oil-cell-free fermentation broth respectively on the corrosion behavior of carbon steel as a function of time in a mineral salts medium using mass loss measurement, electrochemical techniques, scanning electron microscopy (SEM) and energy dispersive X-ray spectra (EDS) analysis. In addition, the antibacterial capability of the oil-cell-free fermentation broth on the SRB and TGB are also implemented.

\section{Materials and methods}

\subsection{Metal sample preparation}

The carbon steel Q235 used in this study contains $99.22 \% \mathrm{Fe}$, $0.37 \% \mathrm{Mn}, 0.20 \% \mathrm{Si}, 0.17 \% \mathrm{C}, 0.03 \% \mathrm{~S}, 0.01 \% \mathrm{P}$ and other trace elements. Sheet specimens of carbon steel with dimensions of $50 \times 25 \times 2 \mathrm{~mm}$ were used for SEM and EDS analysis. Metallic specimens used as working electrode had an exposed area of 1 $\mathrm{cm}^{2}$ in the electrochemical study. The electrical connection was made through copper wire protected with epoxy resin. Prior to the experiments, specimens were successively ground using a series of 240, 400, 800, 1000, 1200 and 2000 grits silicon carbide papers. The polished specimens were subsequently rinsed with deionized (DI) water thrice, then degreased with acetone, sterilized with UV light and immersion in 70\% ethanol for $1 \mathrm{~h}$, and finally dried in a laminar flow cabinet. ${ }^{15}$ The newlyprepared specimens were immediately used in the corrosion experiments.

\subsection{Medium and inoculum cultivation}

Pseudomonas sp. SWP-4 isolated as described in previous study ${ }^{\mathbf{1 0}}$ was stored in glycerol freezer stock at $-40{ }^{\circ} \mathrm{C}$ in a refrigerator. Before each experiment, one Cryo tube was thawed at $35^{\circ} \mathrm{C}$ for $15 \mathrm{~min}$. The preculture was incubated in Luria-Bertani (LB) medium: $10 \mathrm{~g} \mathrm{~L}^{-1}$ tryptone, $5 \mathrm{~g} \mathrm{~L}^{-1}$ yeast extract and $5 \mathrm{~g} \mathrm{~L}^{-1}$ $\mathrm{NaCl}$, while mineral salts medium (MSM) for corrosion experiments contained the following components: $4 \mathrm{~g} \mathrm{~L}^{-1} \mathrm{NaNO}_{3}, 5 \mathrm{~g}$ $\mathrm{L}^{-1} \mathrm{NaCl}, 1 \mathrm{~g} \mathrm{~L}{ }^{-1} \mathrm{KH}_{2} \mathrm{PO}_{4}, 1 \mathrm{~g} \mathrm{~L}^{-1} \mathrm{~K}_{2} \mathrm{HPO}_{4}, 0.2 \mathrm{~g} \mathrm{~L}^{-1} \mathrm{MgSO}_{4}^{-}$ $\cdot 7 \mathrm{H}_{2} \mathrm{O}, 0.2 \mathrm{~g} \mathrm{~L}^{-1} \mathrm{FeSO}_{4} \cdot 7 \mathrm{H}_{2} \mathrm{O}, 0.2 \mathrm{~g} \mathrm{~L}^{-1} \mathrm{CaCl}_{2}, 20 \mathrm{~g} \mathrm{~L}^{-1}$ WCO. Each medium was autoclaved at $121{ }^{\circ} \mathrm{C}$ for $20 \mathrm{~min}$ before use.

\subsection{Cultivation of Pseudomonas sp. SWP-4 at static condition}

In previous work, we have studied the dynamic growth curve of Pseudomonas sp. SWP-4. ${ }^{9}$ In this study, the static growth curve of Pseudomonas sp. SWP-4 was studied with MSM at static condition. The optical density at a wavelength of $600 \mathrm{~nm}\left(\mathrm{OD}_{600}\right)$ of the oil-free broth (diluted by six times with the sterile mineral salts medium) was measured to indicate bacteria densities every $4 \mathrm{~h}$ during the culture period of $420 \mathrm{~h}$ with an ultraviolet spectrophotometer ( $\mathrm{V}-1800$, Kyoto, Japan). Meanwhile, the $\mathrm{pH}$ of the oil-free broth was measured every $12 \mathrm{~h}$ in the whole culture period with Youke $\mathrm{pH}$ meter (PHS-3E, Shanghai, China). Biosurfactant concentration was analyzed with anthronesulfuric acid colorimetric method, ${ }^{35,36}$ and the rhamnose value was calculated from the standard curves prepared with $\mathrm{L}^{-}$ rhamnose (10-90 $\left.\mathrm{mg} \mathrm{L}^{-1}\right)$. The concentration of rhamnolipid was calculated by multiplying rhamnose value with 3.4 , obtained from the correlation of pure rhamnolipid. ${ }^{9,37}$

\subsection{Mineral salts oil-cell-free fermentation broth}

These experiments were performed in $250 \mathrm{~mL}$ flasks containing $100 \mathrm{~mL}$ MSM inoculated with Pseudomonas sp. SWP-4 $2 \mathrm{~mL}$ at $35{ }^{\circ} \mathrm{C}, 150 \mathrm{rpm}$ for 3 days. To acquire the oil-cell-free fermentation broth, the supernatant containing the biosurfactant was separated from the cells and residual oil by centrifuging for $15 \mathrm{~min}$ at $3000 \mathrm{rpm}$. The oil-cell-free broth was stored at $-4{ }^{\circ} \mathrm{C}$ for the following experiments.

\subsection{Weight loss experiments}

Carbon steel specimens with dimensions of $50 \mathrm{~mm} \times 20 \mathrm{~mm} \times$ $5 \mathrm{~mm}$ were used for the weight loss experiments. Weight loss of carbon steel specimens was monitored to evaluate corrosion.

To investigate the corrosion effect of carbon steel specimens in Pseudomonas sp. SWP-4 culture and the oil-cell-free broth, two sets of experiments were designed. In the first set of experiment, the influence of Pseudomonas sp. SWP-4 on the corrosion of carbon steel was investigated. The specimens were immersed in the MSM with and without Pseudomonas sp. SWP-4 for $12,48,96,168,216,348$, and 420 hours. In the second set of experiments, carbon steel specimens were exposed in mineral salts oil-cell-free fermentation broth got sterile deionised water was used as the control for 168, 336, 504, and 672 hours.

All the experiments were conducted in triplicates and the average was taken as the final result. Prior to the experiment, carbon steel specimens were weighed by a high-precision electronic analytical balance recorded as $m_{0}$. After the experiment, the corrosion products and the biofilm grew on the surface of carbon steel specimens during the experiments period were removed following the procedure in the ASTM G1. Specimens 
were weighed again and recorded as $m_{1}$, and the corrosion rate was calculated through the weight loss method. ${ }^{38}$ The corrosion rate was calculated as follows:

$$
v=8.76 \times \frac{m_{0}-m_{1}}{A t \rho}
$$

where $v$ is the average corrosion rate, $\mathrm{mm}$ per year; $m_{0}$ is the sample initial weight, $g ; m_{1}$ is the weight of the sample after removing the corrosion products and biofilm, $g$; $A$ is the area of the specimen, $\mathrm{m}^{2} ; t$ is the exposure time, year; $\rho$ is the density of the metal, $\mathrm{g} \mathrm{cm}^{-3}$.

\subsection{Electrochemical studies}

To measure the Tafel plots and the electrochemical impedance spectroscopy, electrochemical tests were performed in a conventional three-electrode glass corrosion cell with a capacity of $250 \mathrm{~mL}$. An $\mathrm{Ag} / \mathrm{AgCl}$ electrode connected to the working electrode (WE) through a Luggin's capillary was used as the reference electrode and a carbon electrode was used as the counter electrode (CE). All electrochemical tests were conducted using a computer-controlled system CHI650E (Shanghai Chenhua Instrument Company, China). Each electrochemical test was performed at a steady open circuit potential (OCP), $E_{\mathrm{OCP}}$.

2.6.1. Tafel polarization measurements. The Tafel polarization curves were recorded at a scan rate of $1 \mathrm{mV} \mathrm{s}^{-1}$ within the range of -250 to $250 \mathrm{mV}$ versus the open circuit potential to determine the corrosion current density $\left(i_{\text {corr }}\right)$.

2.6.2. Electrochemical impedance spectroscopy measurements. The electrochemical impedance spectroscopy (EIS) was performed at a steady OCP and at an alternating current amplitude of $10 \mathrm{mV}$ sine wave at frequencies ranging from 10 $\mathrm{kHz}$ to $1 \mathrm{~Hz}$; Zview software was used for EIS data analysis.

\subsection{Surface topography analysis with SEM-EDS}

The bacteria-colonized specimens underwent fixation and dehydration according to the procedures reported in literature before SEM and EDS analysis. ${ }^{39}$ To assess the corrosion damage of specimens under the biofilms, ultrasonic treatment was used to remove biofilm. The specimens were immersed in a beaker with $100 \mathrm{~mL} 0.1 \mathrm{M}$ EDTA solution, ${ }^{\mathbf{4 0 , 4 1}}$ and, then, ultrasonicated for $15 \mathrm{~min}$ in a sonication bath with a frequency of $40-50 \mathrm{kHz}$ to remove the corrosion products and the biofilms. The prepared specimens were then sputter-coated with gold/palladium, and subsequently detected with a scanning electron microscope and a energy dispersive X-ray spectra (JEOL JSM-7500F model \& XMAX50). The imaging sites for SEM were typically chosen on the specimen surface to be representative of the entire surface of the carbon steel specimens.

\subsection{Evaluation of antibacterial effects}

To mitigate the corrosion of carbon steel by harmful bacteria through reducing the quantities of them, the antibacterial effects of oil-cell-free fermentation broth were examined separately on SRB and TGB, and the concentrations of rhamnolipid in the broths were $32 \mu \mathrm{g} \mathrm{mL} \mathrm{m}^{-1}, 96 \mu \mathrm{g} \mathrm{mL}^{-1}, 160 \mu \mathrm{g} \mathrm{mL}^{-1}, 320 \mu \mathrm{g}$ $\mathrm{mL}^{-1}$, and $640 \mu \mathrm{g} \mathrm{mL}^{-1}$, respectively. The bacteria were all incubated at $35^{\circ} \mathrm{C}$ for $24 \mathrm{~h}$, and then the most probable number (MPN) method was used to assess the quantities of bacteria. ${ }^{42}$

\section{Results and discussion}

\subsection{Growth curve of Pseudomonas sp. SWP-4}

The growth curve of Pseudomonas sp. SWP-4 under the static cultivation at $30{ }^{\circ} \mathrm{C}$ was presented in Fig. 1 . It can be seen that the growth curve of Pseudomonas sp. SWP-4 followed the traditional bacterial growth, i.e. lag phase, exponential phase, stationary phase and death phase. Before $36 \mathrm{~h}$, the bacteria were at lag phase; during 36-120 h, it went into exponential phase, the number of active bacteria increased rapidly. It was found that rhamnolipid production accelerated in the exponential phase. In the death phase, although active bacterial concentration decreased significantly, rhamnolipid concentration remained at similar level as steady phase.

\subsection{Corrosion of carbon steel in sterile medium and Pseudomonas sp. SWP-4 inoculated medium based on weight loss method}

Fig. 2 shows dependence of the corrosion rate of specimens over the time during the corrosion process lasting for $420 \mathrm{~h}$ exposed in sterile medium and medium containing bacterium. In both cases, differences could be seen between samples exposed to sterile medium and medium containing bacterium. The corrosion rates of the steel specimens without and with Pseudomonas sp. SWP-4 calculated through the eqn (1) are shown in Fig. 2 respectively. During the first $12 \mathrm{~h}$, the corrosion rates in sterile medium was $0.2566 \mathrm{~mm}$ per year a bit more than that in medium containing Pseudomonas sp. SWP-4, $0.1961 \mathrm{~mm}$ per year. However, during the first $96 \mathrm{~h}$, the corrosion rates of the carbon steel specimens with Pseudomonas sp. SWP-4 showed a little more than that without Pseudomonas sp. SWP-4. After specimens immersed for $420 \mathrm{~h}$, these data confirmed that when bacterium was added into the medium, the corrosion rate $0.0136 \mathrm{~mm}$ per year was approaching to without bacterium,

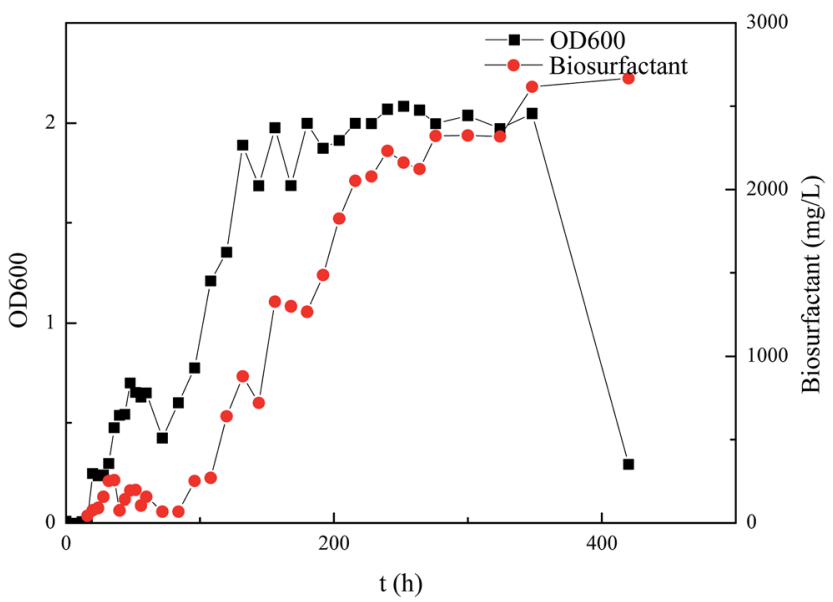

Fig. 1 Growth curve of Pseudomonas sp. SWP-4 and rhamnolipid concentration curves. 


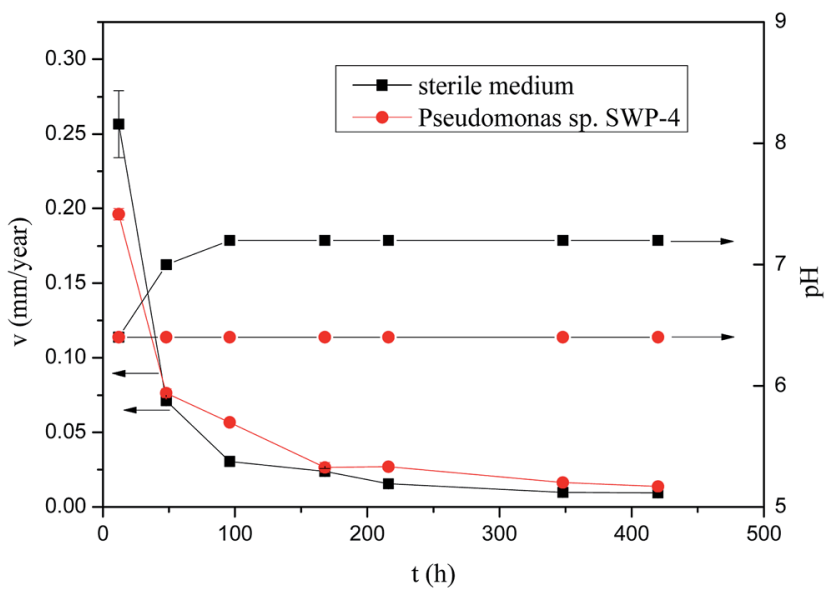

Fig. 2 Time dependence of corrosion rate of carbon steel and $\mathrm{pH}$ in sterile medium and medium containing Pseudomonas sp. SWP-4.

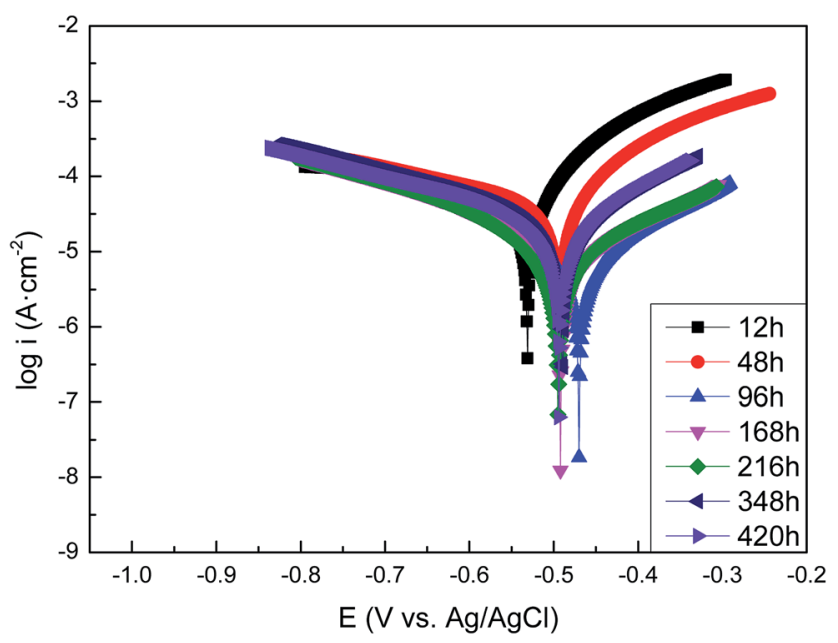

Fig. 3 Tafel plots of the carbon steel specimens in the sterile medium after different exposure periods: 12 h, 48 h, 96 h, 168 h, 216 h, 348 h, $420 \mathrm{~h}$.

$0.00935 \mathrm{~mm}$ per year, which meant Pseudomonas sp. SWP-4 influenced carbon steel efficiently and caused slight corrosion. It was quite different from the severely corrosive bacteria, Pseudomonas aeruginosa, reported by E. Hamzah, ${ }^{12}$ with the corrosion rate of more than $0.1 \mathrm{~mm}$ per year. The $\mathrm{pH}$ values showed in Fig. 2. After inoculated with Pseudomonas sp. SWP-4, it increased to 7.2 .

\subsection{Corrosion of carbon steel in sterile medium and Pseudomonas sp. SWP-4 inoculated medium based on electrochemical measurements}

3.3.1. The polarization curves of carbon steel in sterile and Pseudomonas sp. SWP-4 inoculated media. The polarization curves of the carbon steel after exposure to the sterile medium and the medium containing Pseudomonas sp. SWP-4 for different periods are shown in Fig. 3 and 4, respectively. The data of the electrochemical corrosion parameters such as the

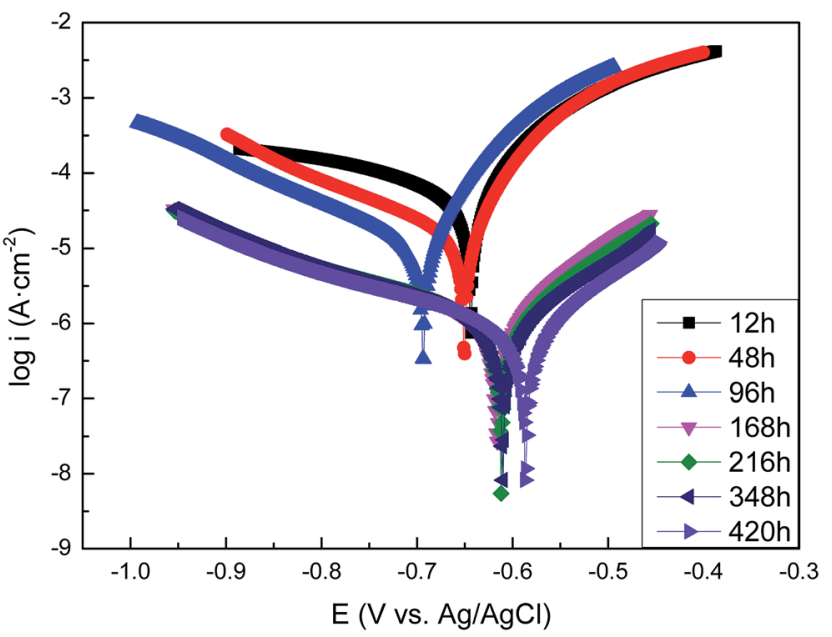

Fig. 4 Tafel plots of the carbon steel specimens in the Pseudomonas sp. SWP-4 inoculated medium after different exposure periods: $12 \mathrm{~h}$, 48 h, 96 h, 168 h, 216 h, 348 h, 420 h.

corrosion potentials $\left(E_{\text {ocp }}\right)$, the Tafel slope (anodic slope $\beta_{\mathrm{a}}$ and cathodic slope $\beta_{\mathrm{c}}$ ), and corrosion current densities $\left(i_{\text {corr }}\right)$ are further analyzed with the extrapolation of the polarization and listed in Tables 1 and 2. At the beginning of the experiments, the $E_{\text {corr }}$ and $i_{\text {corr }}$ value of Pseudomonas sp. SWP-4-colonized carbon steel electrode were slightly more positive than the steel specimens in sterile medium, indicating that the bacterium induced an increase in the corrosion rate of carbon steel and its metabolites. In comparison with carbon steel in sterile medium for $420 \mathrm{~h}$, the $E_{\text {corr }}$ of the carbon steel underwent a negative shift of about $93 \mathrm{mV}$ by the effect of the Pseudomonas sp. SWP-4 bacterium.

It is clearly seen from Fig. 3 that corrosion current densities, $i_{\text {corr }}$, decreased with exposure periods in the sterile medium, suggesting a decrease in the corrosion rate of the carbon steel with time owing to the formation of the protective oxide film. This was in good agreement with the results that the corrosion potential, $E_{\text {corr }}$, shifted from -0.531 to $-0.490 \mathrm{~V}$ (vs. $\left.\mathrm{Ag} / \mathrm{AgCl}\right)$ after $420 \mathrm{~h}$ immersion.

For the exposure to the medium containing Pseudomonas sp. SWP-4, it was observed that, corrosion potential shifted from $-0.644 \mathrm{~V}$ to $-0.694 \mathrm{~V}$ (vs. $\mathrm{Ag} / \mathrm{AgCl}$ ) from $12 \mathrm{~h}$ to $96 \mathrm{~h}$, corresponding to exponential phase of bacteria growth. In addition, the corrosion current densities, $i_{\text {corr }}$, decreased more slowly than that without Pseudomonas sp. SWP-4, which implied that bacteria may increase the corrosion rate in the exponential phase. Regarding to polarization curves, the cathodic branch in the MSM was attributed to the dissolved oxygen reduction; whereas, in the presence of Pseudomonas sp. SWP-4, the bacteria consumed the oxygen in the solution during the first $96 \mathrm{~h}$, as a result, cathodic branch decreasing from -315 to $-187 \mathrm{mV}$ $\mathrm{dec}^{-1}$ refers to water reduction and hydrogen production. While the decrease in anodic branch from 104 to $81 \mathrm{mV} \mathrm{dec}^{-1}$ indicates that electron transfer became easier from the anodic site after the formation of the biofilm. After the exponential phase, it was found that $i_{\text {corr }}$ reduced dramatically from 11.96 to 0.95 
Table 1 Tafel analysis of polarization curves of the carbon steel in the sterile medium after different exposure time

\begin{tabular}{llcccc}
\hline$T(\mathrm{~h})$ & $E_{\text {OCP }}(\mathrm{V} v s . \mathrm{Ag} / \mathrm{AgCl})$ & $I_{\text {corr }}(\mu \mathrm{A})$ & $i_{\text {corr }}\left(\mu \mathrm{A} \mathrm{cm}{ }^{-2}\right)$ & $\beta_{\mathrm{a}}\left(\mathrm{mV} \mathrm{dec}^{-1}\right)$ & 119 \\
\hline 12 & -0.531 & 57.62 & 57.62 & 134 & -300 \\
48 & -0.493 & 58.30 & 58.30 & 160 & -342 \\
96 & -0.47 & 8.125 & 8.125 & 170 & -161 \\
168 & -0.492 & 10.46 & 10.46 & 173 & -163 \\
216 & -0.495 & 7.543 & 7.543 & 149 & -163 \\
348 & -0.49 & 24.48 & 24.48 & 150
\end{tabular}

Table 2 Tafel analysis of polarization curves of the carbon steel in the Pseudomonas sp. SWP-4 inoculated medium after different exposure periods

\begin{tabular}{llllll}
\hline$T(\mathrm{~h})$ & $E_{\text {OCP }}(\mathrm{V} v s . \mathrm{Ag} / \mathrm{AgCl})$ & $I_{\text {corr }}(\mu \mathrm{A})$ & $i_{\text {corr }}\left(\mu \mathrm{A} \mathrm{cm}^{-2}\right)$ & $\beta_{\mathrm{a}}\left(\mathrm{mV} \mathrm{dec}^{-1}\right)$ & 104 \\
\hline 12 & -0.644 & 68.51 & 68.51 & $\beta_{\mathrm{c}}\left(\mathrm{mV} \mathrm{dec}^{-1}\right)$ \\
48 & -0.650 & 23.16 & 23.16 & 81 & -315 \\
96 & -0.694 & 16.22 & 16.22 & 107 & -197 \\
168 & -0.616 & 1.336 & 1.336 & 116 & -243 \\
216 & -0.612 & 1.286 & 1.286 & 123 & -245 \\
348 & -0.612 & 1.174 & 1.174 & 118 & -236 \\
420 & -0.587 & 0.950 & 0.950 & & \\
\hline
\end{tabular}

$\mu \mathrm{A} \mathrm{cm}^{-2}$ which was smaller than the value without Pseudomonas sp. SWP-4. It was speculated that this was probably caused by the inhibiting effect of the biosurfactant produced by Pseudomonas sp. SWP-4. It was different from the Pseudomonas investigated by S. J. Yuan. ${ }^{23}$ The anodic Tafel slopes and cathodic Tafel slopes both increased, which supposed that the surface products made electron transfer became more difficult from the anodic site after the biosurfactant absorbed on the surface.

3.3.2. The EIS of carbon steel in the sterile and Pseudomonas sp. SWP-4 inoculated medium. EIS was conducted to illuminate the adhesion mechanism of Pseudomonas sp. SWP-4 to specimen surfaces, which was a complicated process affected by various physicochemical properties such as bacterial cells, metabolites and substratum surfaces. ${ }^{43}$

Fig. 5a, 6a and 7a respectively shows typical Nyquist and Bode plots determined for carbon steel in sterile medium at different immersion periods. Fig. 5a shows Nyquist plots including a capacitive loop at high to medium frequencies and a straight line (Warburg impedance) at low frequencies. The presence of Warburg impedance reflects cathodic diffusion of dissolved oxygen from bulk solution to carbon steel electrode surface. The impedance value increased with exposure time because passive layers were formed on the metal surface. To describe the impedance response of corrosion in sterile medium, we proposed a similar circuit with two similar circuit, one relaxation-time constant for before $96 \mathrm{~h}$ (Fig. 8a) and two relaxation time constants after $96 \mathrm{~h}$ (Fig. 8b). In the circuit, $R_{\mathrm{s}}$ is the resistance of solution, $R_{\mathrm{b}}$ is pore resistance and $R_{\mathrm{ct}}$ is the resistance of charge transfer, $\mathrm{CPE}_{\mathrm{b}}$ is the Constant Phase Element (CPE) parameter for the inhomogeneous layer, $\mathrm{CPE}_{\mathrm{dl}}$ is parameter for the electrical double layer and $C$ is parameter for the double layer, $W$ is parameter for the Warburg impedance.
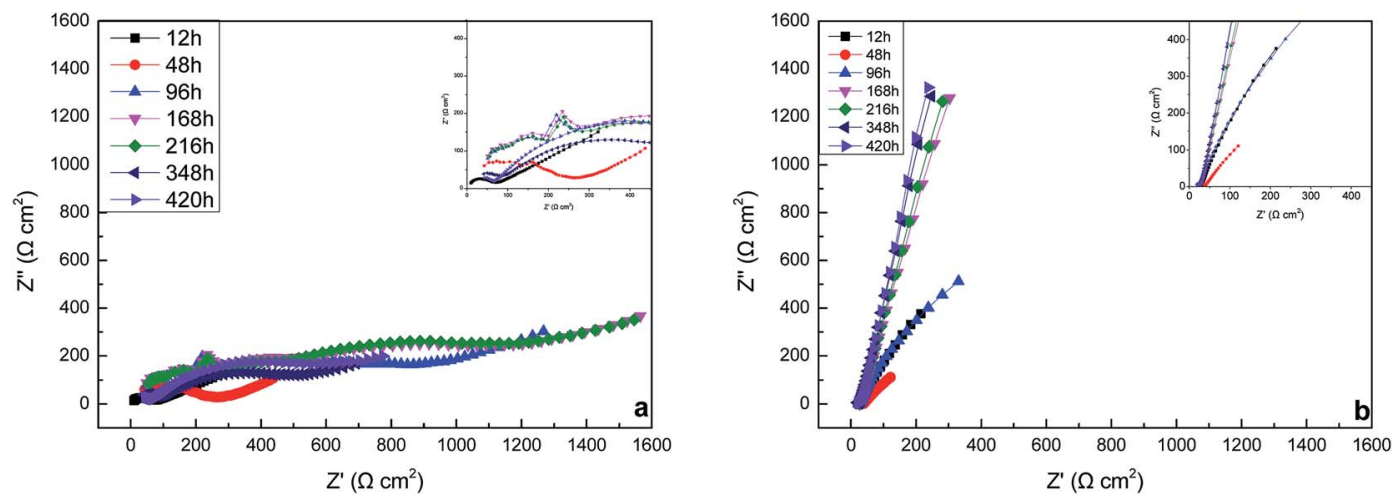

Fig. 5 Nyquist plots of the specimens in the sterile medium (a) and medium containing Pseudomonas sp. SWP-4 (b) after different exposure periods: 12 h, 48 h, 96 h, 168 h, 216 h, 348 h, 420 h. 

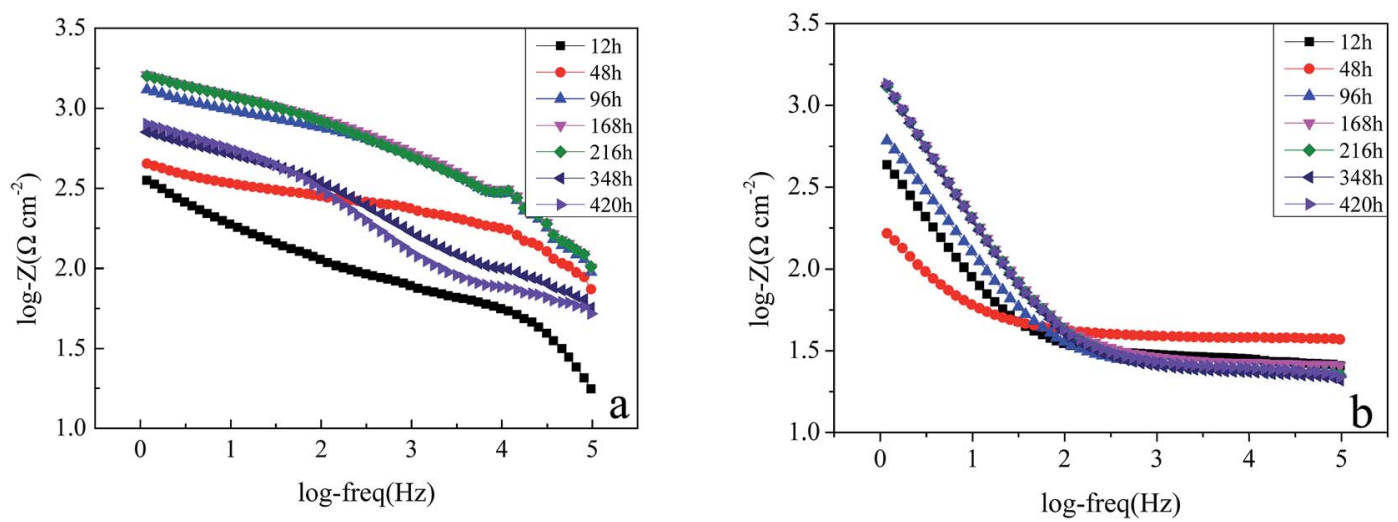

Fig. 6 Magnitude Bode plots of the specimens in the sterile medium (a) and medium containing Pseudomonas sp. SWP-4 (b) after different exposure periods: 12 h, 48 h, 96 h, 168 h, 216 h, 348 h, 420 h.
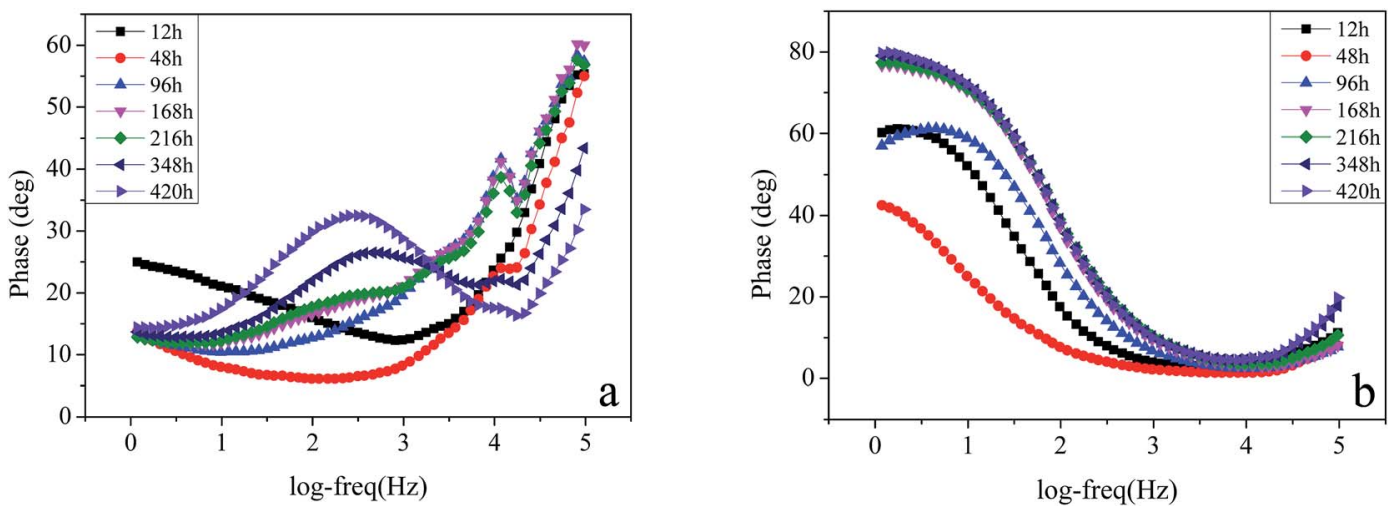

Fig. 7 Phase Bode plots of the specimens (a) in the sterile medium and medium containing Pseudomonas sp. SWP-4 (b) after different exposure periods: 12 h, 48 h, 96 h, 168 h, 216 h, 348 h, 420 h.

The second time constant represented the formation of a corrosion product and oxide layer on a metal surface. ${ }^{44}$

Nyquist and Bode plots for carbon steel in medium with SWP-4 at different immersion periods are illustrated in Fig. 5b, $6 \mathrm{~b}$ and $7 \mathrm{~b}$. Before $96 \mathrm{~h}$ (including $96 \mathrm{~h}$ ), since bacterial metabolism was very active, the physical and chemical characteristics of medium containing bacteria were changeable due to the production of metabolites. The diameters of impedance loops in the Nyquist plots (Fig. 5b) decreased with time before $96 \mathrm{~h}$, implying an accelerated corrosion of the carbon steel specimens. When bacteria attached to specimens (for 96 h), Nyquist plots was fitted with a two-time constant

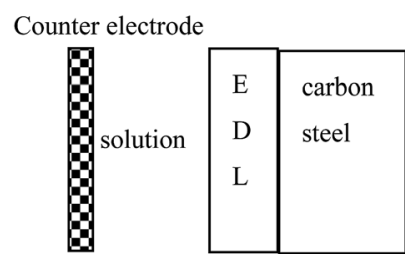

Counter electrode

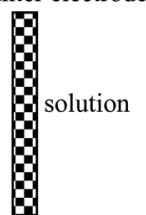

$\mathbf{a}$

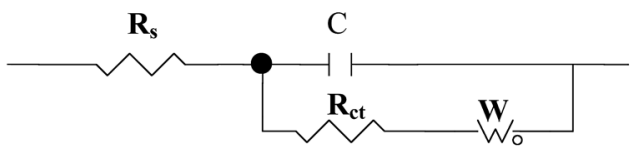

b

\begin{tabular}{|l|l|l|}
\hline porous & E & carbon \\
passive & D & steel \\
film & L & \\
& & \\
\hline
\end{tabular}

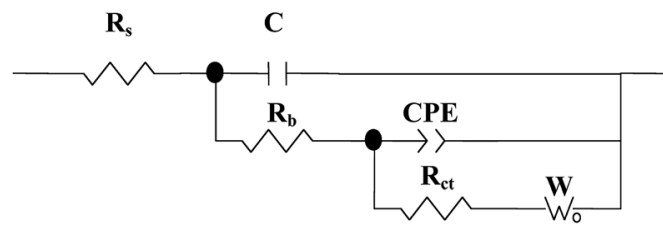

Fig. 8 Two physical models and the corresponding equivalent circuits used for fitting the impedance spectra of the specimens in the sterile medium. Equivalent circuits: (a) and (b). 

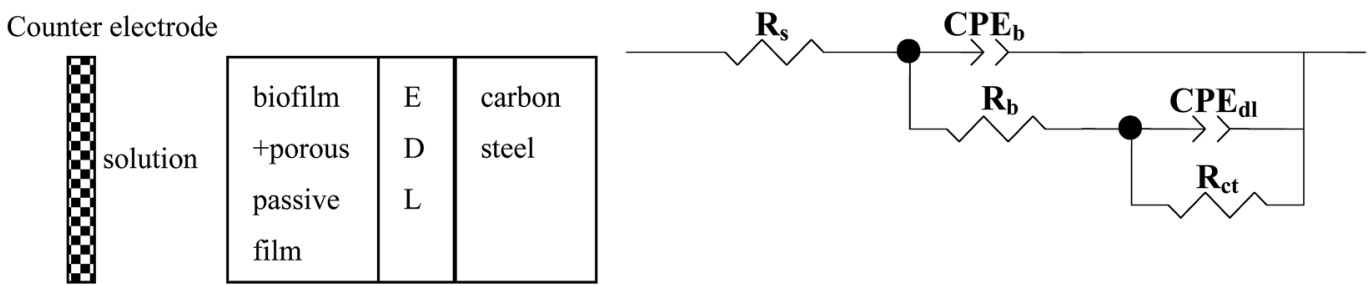

b

Counter electrode

\begin{tabular}{|l|l|l|l|}
\cline { 2 - 3 } solution & $\begin{array}{l}\text { biofilm } \\
\text { +porous }\end{array}$ & D & carbon \\
passive & L & \\
film & & \\
\hline
\end{tabular}

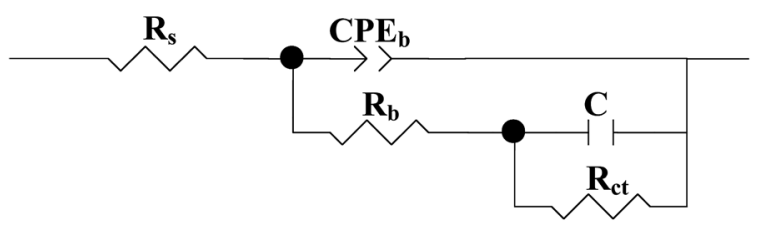

Fig. 9 Two physical models and the corresponding equivalent circuits used for fitting the impedance spectra of the specimens in the Pseudomonas sp. SWP-4-incubated medium. Equivalent circuits: (a) and (b).

Table 3 Fitting parameters of impedance spectra of specimens in the sterile medium after different exposure time

\begin{tabular}{|c|c|c|c|c|c|c|c|c|c|c|}
\hline 12 & 6.004 & $9.52 \times 10^{-2}$ & & & & 27.79 & 59.59 & $1.26 \times 10^{-3}$ & 0.1700 & 0.0013 \\
\hline 96 & 33.32 & $2.46 \times 10^{-2}$ & 206.80 & 14.6 & 0.55803 & 545.00 & 9.345 & $3.52 \times 10^{-7}$ & 0.1606 & 0.0053 \\
\hline 168 & 28.97 & $2.13 \times 10^{-2}$ & 196.20 & 41.2 & 0.45212 & 1072.0 & 6.983 & $1.55 \times 10^{-6}$ & 0.1920 & 0.0049 \\
\hline 216 & 37.80 & $2.34 \times 10^{-2}$ & 208.00 & 44.1 & 0.47078 & 1103.0 & 4.858 & $1.22 \times 10^{-6}$ & 0.1982 & 0.0045 \\
\hline
\end{tabular}

equivalent circuit showed in Fig. 9a and the results were listed in Table 4. A constant phase element (CPE) and capacitance were used due to the microscopic roughness of a surface. ${ }^{34-37}$ Hence, corrosive biofilm formation initially increased, leading to decreased impedance value. Subsequently, corrosion impedance increased from 96 h. From 96 h to 216 h, another two-time constant circuit shown in Fig. $9 \mathrm{~b}$ was used to analyze the impedance spectra and it was found that $\mathrm{CPE}_{\mathrm{b}}-\mathrm{T}$ and $\mathrm{CPE}_{\mathrm{dl}}$ $\mathrm{T}$ increased to $60 \mu \Omega^{-1} \mathrm{~s}^{n} \mathrm{~cm}^{-2}$ and $70 \mu \Omega^{-1} \mathrm{~s}^{n} \mathrm{~cm}^{-2}$, respectively. The accumulation of rhamnolipid over the time increased $R_{\text {ct. }}$. For $348 \mathrm{~h}$ and $420 \mathrm{~h}, C$ decreased to a stable value i.e. $23 \mu \mathrm{F} \mathrm{cm}^{-2}$. The high concentration of rhamnolipid at this time increased $R_{\mathrm{ct}}$, and thus decreased corrosion rate. The values of Chi-square $\chi^{2}$ were all around $10^{-3}$, exhibiting the goodness of the equivalent circuit fits, as listed in Tables 3 and 4.

\subsection{Corrosion of carbon steel in sterile medium and Pseudomonas sp. SWP-4 inoculated medium based on SEM micrographs and EDS spectrum}

SEM micrographs and EDS spectrum to determine microbiologically influenced metal corrosion are used to observe the microbial adhesion and the formation of the porous biofilm. ${ }^{21,23}$ Fig. 10a shows that the surfaces of carbon steel exposed in sterile MSM for $420 \mathrm{~h}$ was covered by a corrosive oxide layer with large crates. Fig. 10b shows carbon steel surface after immersion in the medium with the presence of Pseudomonas sp. SWP4 surfaces extensively covered with a thick biofilm layer, while Fig. 10c and e shows the intact biofilm-covered adhesion zones on carbon steel surface following compact bacterial exposure. EDS was used to obtain elemental information from corrosion products of typical areas on the surface of the carbon steel. The EDS analysis showed that oxide percentage of the specimens surface immersed in the sterile medium was $54.15 \%$ whereas the specimens immersed in the medium containing bacterium was $43.48 \%$. It also showed that high amounts of $\mathrm{Na}, \mathrm{Mg}, \mathrm{K}, \mathrm{Ca}$ as metabolic by-products (Table 5), which were ascribed to the halophilic characteristic. As a result, Pseudomonas sp. SWP-4 caused a reduction in the oxide percentage due to aerobic respiration. The elemental information from the corrosion products on the specimens surfaces was shown in Table 5. The results were in agreement with the previous study, ${ }^{15}$ microbial adhesion and the consequent biofilm formation resulted in metal ion and chloride ion accumulation and induced corrosion. 
Table 4 Fitting parameters of impedance spectra of specimens in the medium innovated Pseudomonas sp. SWP-4 after different exposure time

\begin{tabular}{|c|c|c|c|c|c|c|c|c|c|}
\hline$t / \mathrm{h}$ & $R_{\mathrm{S}} / \Omega \mathrm{cm}^{-2}$ & $\mathrm{CPE}_{\mathrm{b}}-\mathrm{T} / \mu \Omega^{-1} \mathrm{~s}^{n} \mathrm{~cm}^{-2}$ & $\mathrm{CPE}_{\mathrm{b}}-\mathrm{P}$ & $R_{\mathrm{p}} / \Omega \mathrm{cm}^{-2}$ & $C / \mu \mathrm{F}$ & $\mathrm{CPE}_{\mathrm{dl}}-\mathrm{T} / \mu \Omega^{-1} \mathrm{~s}^{n} \mathrm{~cm}^{-2}$ & $\mathrm{CPE}_{\mathrm{dl}}-\mathrm{P}$ & $R_{\mathrm{ct}} / \Omega \mathrm{cm}^{-2}$ & $\chi^{2}$ \\
\hline 12 & 27.86 & 440 & 0.7253 & 13.46 & 68.8 & & & 3226 & 0.0035 \\
\hline 48 & 38.05 & 1414 & 0.697 & 79.5 & 159 & & & 448.2 & 0.0053 \\
\hline 168 & 26.2 & 60.8 & 0.8747 & 12.16 & & 73.3 & 0.87169 & $1.52 \times 10^{5}$ & 0.0016 \\
\hline 216 & 23.32 & 57.3 & 0.8739 & 11.83 & & 79.7 & 0.87036 & $4.73 \times 10^{5}$ & 0.0026 \\
\hline 348 & 23.13 & 110 & 0.8491 & 40.87 & 23.2 & & & $1.51 \times 10^{11}$ & 0.0089 \\
\hline
\end{tabular}

Fig. 11a illustrates the surface of the carbon steel immersed in the sterile medium after corrosion products were removed, which suggested that anions like chloride in the MSM that probably accelerated the corrosion rate. Fig. 11b shows the surface of the carbon steel corrosion immersed in the medium containing Pseudomonas sp. SWP-4 after corrosion products were removed. It clearly showed that the surface attached by porous biofilm and corrosion products was tougher than other
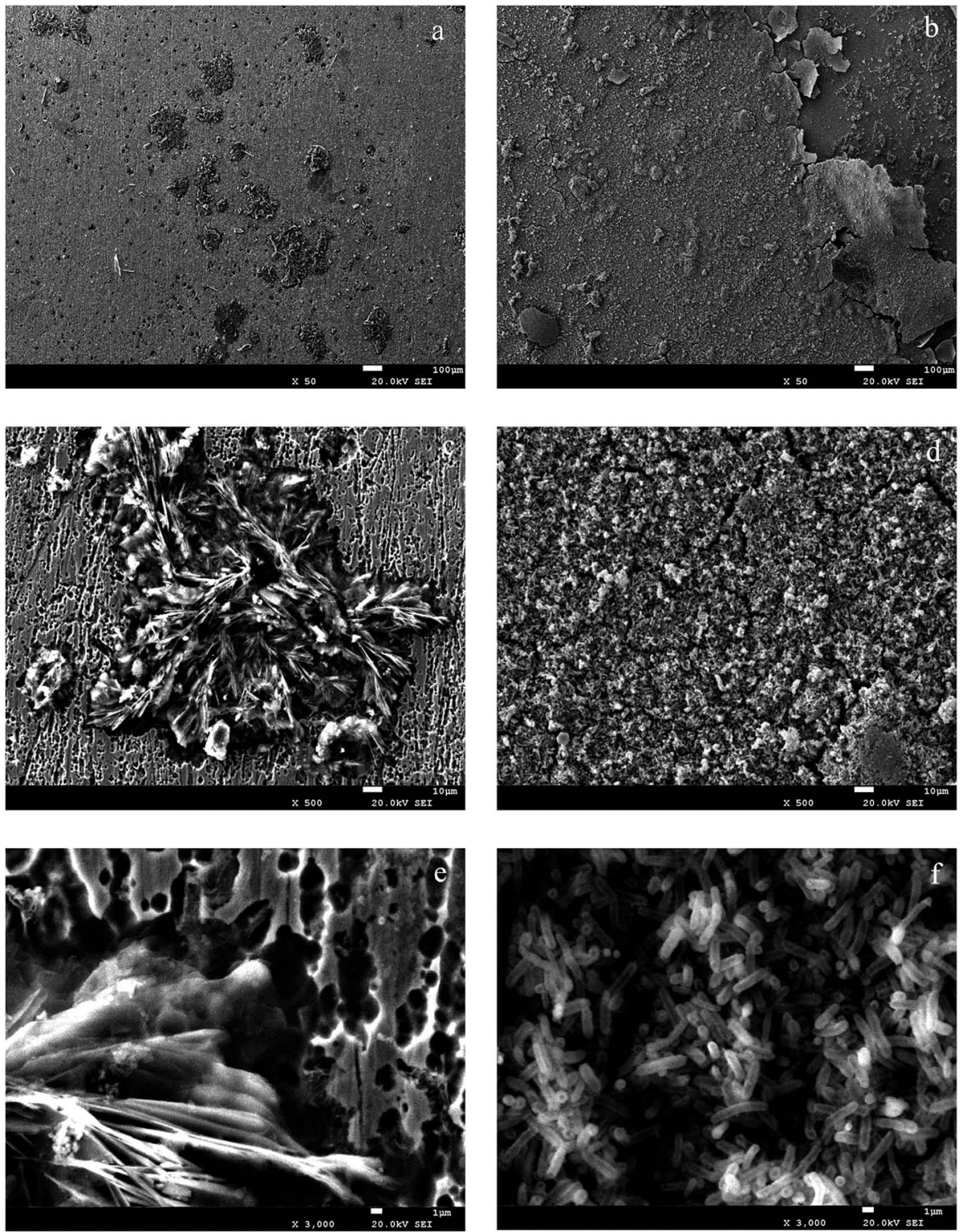

Fig. 10 SEM images of products-attached and bacteria-colonized specimens after $420 \mathrm{~h}$ : (a), (c) and (e) (sterile medium); (b), (d) and (f) (medium with bacteria). 
Table 5 EDS spectrum of carbon steel surfaces exposed to sterile and containing bacteria medium

\begin{tabular}{|c|c|c|c|c|c|c|c|c|}
\hline & $\mathrm{C} / \%$ & $\mathrm{O} / \%$ & $\mathrm{Na} / \%$ & $\mathrm{Mg} / \%$ & $\mathrm{P} / \%$ & $\mathrm{~K} / \%$ & $\mathrm{Ca} / \%$ & $\mathrm{Fe} / \%$ \\
\hline Sterile medium & 30.45 & 54.15 & 0.27 & 0.26 & 5.15 & 0.07 & 0.17 & 9.48 \\
\hline Pseudomonas sp. SWP-4 & 39.85 & 43.48 & 0.55 & 0.53 & 4.65 & 0.2 & 0.62 & 10.12 \\
\hline
\end{tabular}
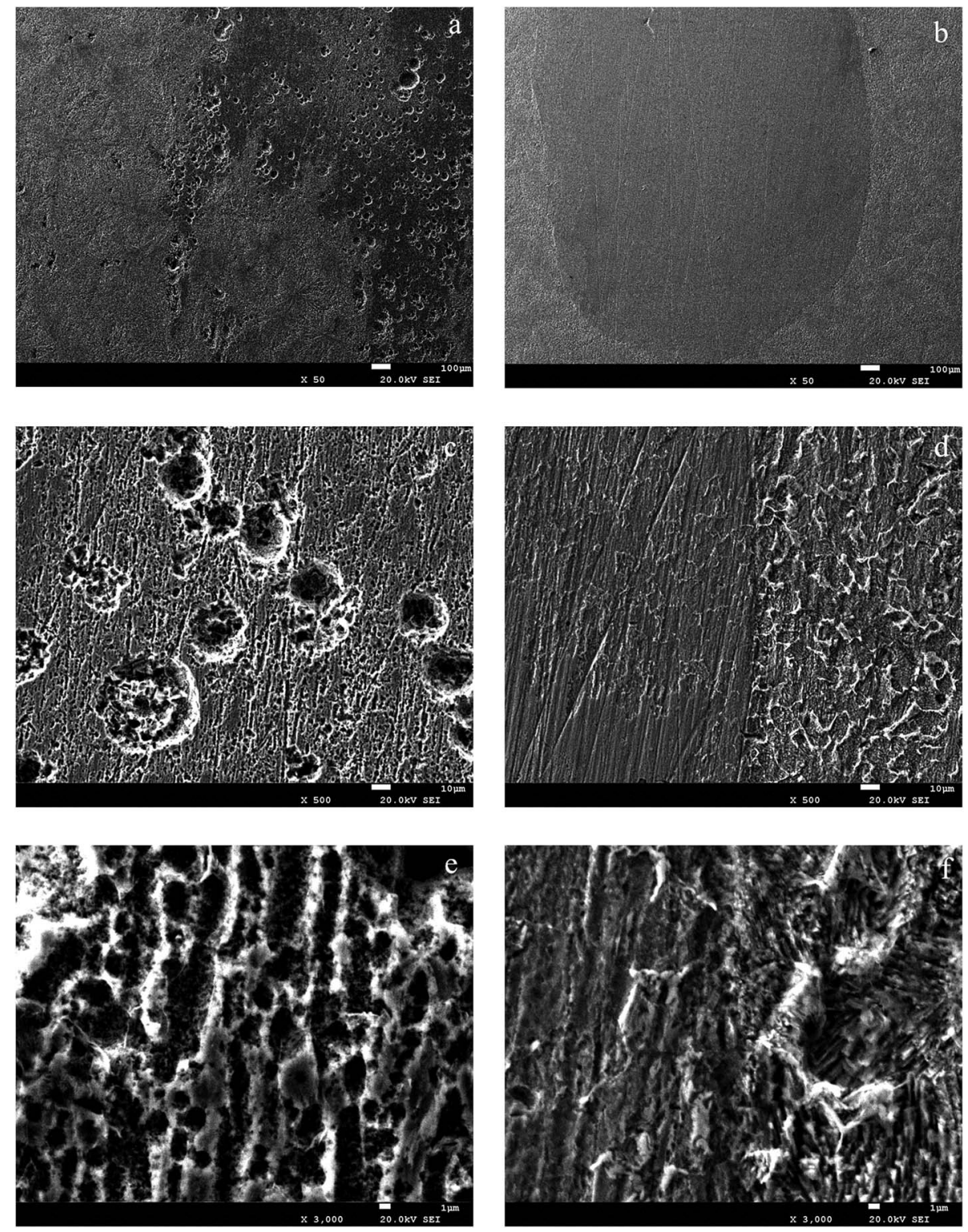

Fig. 11 SEM images of the carbon steel surfaces after corrosion products were removed: (a), (c) and (e) (sterile medium); (b), (d) and (f) (medium with bacteria).

surfaces with compacted biofilm. However, the corrosion cracks were not as serious as the marine halophilic bacteria, Pseudomonas sp. ${ }^{15}$ Combining the weight loss assessment and electrochemical measurements, we deduced that after $216 \mathrm{~h}$, the surface of the carbon steel was covered with rhamnolipid that inhibited the corrosion of carbon steel. Thus, it was the rhamnolipid with high concentration that inhibited the corrosion with time prolonged.

\subsection{Corrosion of carbon steel in sterile deionised water and} oil-cell-free fermentation broth based on weight loss method

The corrosion rates during the corrosion process for $672 \mathrm{~h}$ immersed in the sterile deionised water and the fermentation broth containing rhamnolipid of $2.87 \mathrm{~g} \mathrm{~L}^{-1}$ secreted by Pseudomonas sp. SWP-4 were presented in Fig. 12. The corrosion rates $0.0059 \mathrm{~mm}$ per year of the steel coupons exposed in the fermentation broth were lower than that in the sterile deionised 


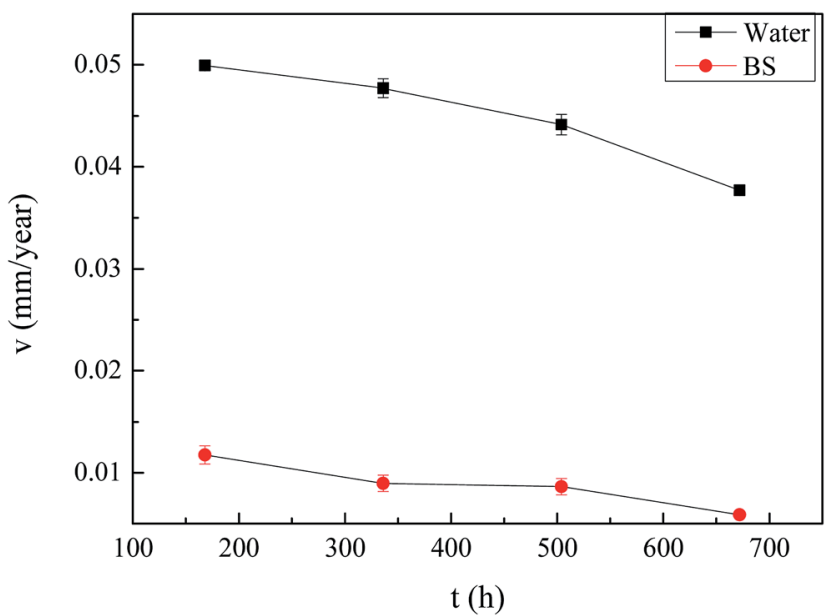

Fig. 12 Time dependence of corrosion rate changes of carbon steel immersed in sterile deionised water and the fermentation broth.

Table 6 Tafel analysis of polarization curves of the carbon steel in the deionized sterile water (DI water) and in the oil-cell-free fermentation broth

\begin{tabular}{|c|c|c|c|c|c|}
\hline & $\begin{array}{l}E_{\mathrm{OCP}} \\
\text { (V vs. } \mathrm{Ag} / \mathrm{AgCl} \text { ) }\end{array}$ & $\begin{array}{l}i_{\text {corr }} / \\
\mu \mathrm{A}\end{array}$ & $\begin{array}{l}I_{\text {corr }} / \\
\mu \mathrm{A} \mathrm{cm}^{-2}\end{array}$ & $\begin{array}{l}\beta_{\mathrm{a}} / \\
\mathrm{mV}^{-1}\end{array}$ & $\begin{array}{l}\beta_{\mathrm{c}} / \\
\mathrm{mV}^{-1}\end{array}$ \\
\hline DI water & -0.461 & 2.62 & 2.62 & 5.049 & 4.871 \\
\hline $\begin{array}{l}\text { Fermentation } \\
\text { broth }\end{array}$ & -0.891 & 2.59 & 2.59 & 3.401 & 8.838 \\
\hline
\end{tabular}

water $0.0377 \mathrm{~mm}$ per year. It obviously showed the fermentation broth itself didn't increase corrosion rate. The result agreed with T. Meylheuc, who proved that the adsorption of rhamnolipid produced by Pseudomonas fluorescens inhibited the AISI 304 corrosion against the chloride diffusion. ${ }^{24}$ This indicated the efficiency of the biosurfactant, rhamnolipid, which acted as

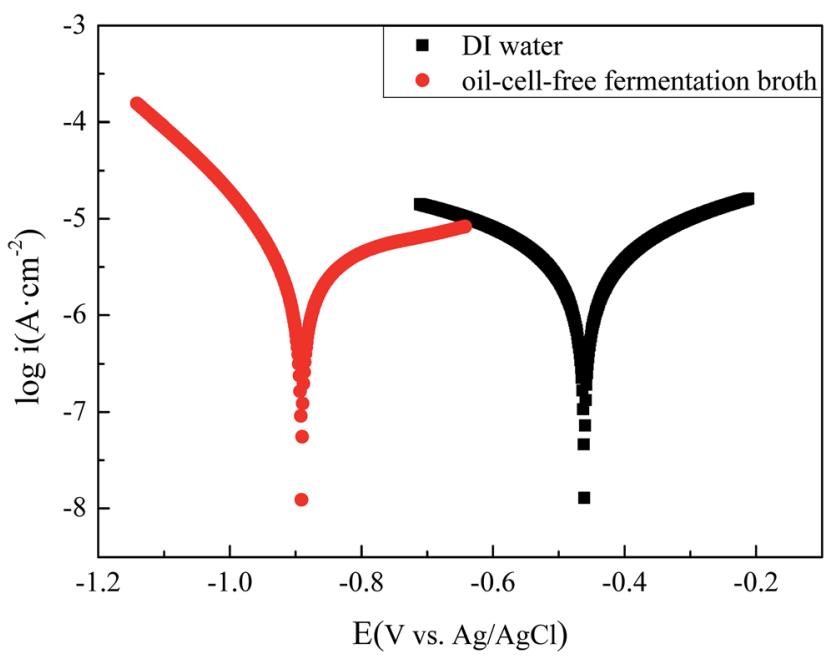

Fig. 13 Tafel plots of the carbon steel specimens in the deionized sterile water (DI water) and in the oil-cell-free fermentation broth. a quickly-appearing barrier to the oxide, leading to the decrease of corrosion rate.

\subsection{Corrosion of carbon steel in sterile deionised water and oil-cell-free fermentation broth based on electrochemical measures}

Fig. 13 shows the polarization curves of the carbon steel respectively immersed in deionized sterile water and in the oil-cell-free fermentation broth. The data of the electrochemical corrosion parameters are analyzed with the extrapolation of the polarization and listed in Table 6 . The $i_{\text {corr }}\left(2.59 \mu \mathrm{A} \mathrm{cm}^{-2}\right)$ reflected that the corrosion of carbon steel immersed in the oil-cell-free fermentation broth, which was smaller than that $(2.62 \mu \mathrm{A}$ $\mathrm{cm}^{-2}$ ) immersed in the deionized sterile water. The consequence was in agreement with weight loss result, and the corrosion rates in the fermentation broth were lower than that in the sterile deionised water which indicated that the electrochemical corrosion of oil-cell-free fermentation broth was so mild.

\subsection{Corrosion of carbon steel in sterile deionised water and oil-cell-free fermentation broth based on SEM micrographs}

As shown on the SEM observations (Fig. 14), the carbon steel immersed in the oil-cell-free fermentation broth almost remained intact, while pits had a low diameter and grew in depth the surfaces immersed in sterile deionised water. For samples conditioned by the biosurfactant, the protective oxide layer did not have time to develop because the adsorption of the biosurfactant occurred very quickly. When the sample was immersed in sterile deionised water without the biosurfactant, the oxide layer was more compact, and the number of defects increased, as shown in Fig. 14(a, c and e) which led to a higher density of pits. At these conditions the corrosion propagated much easily on the surface.

\subsection{Antibacterial effects of oil-cell-free fermentation broth}

The results about inhibitory activities of the oil-cell-free fermentation broth against 2 reference harmful bacteria in oil field: SRB and TGB were shown in Table 7. After $24 \mathrm{~h}$ incubation, it was obviously seen that oil-cell-free fermentation broth containing $96 \mu \mathrm{g} \mathrm{mL} \mathrm{mL}^{-1}$ rhamnolipid apparently manifested a good antibacterial capability on the SRB and the TGB. The results showed agreement with that Haifarajollah et al. who had reported rhamnolipid adsorbing on a plasma treated polypropylene surface showed appropriate antimicrobial property against the bacteria, i.e. S.aureus, B. subtilis and K. pneumonia, in food and pharmaceutical industries. ${ }^{31}$

Corrosion never stops but its scale and severity could be reduced. One of the best known methods for protection against corrosion is to use biocide. Biocide has been proved that could control the corrosion of different metals and alloys. In the light of that, it's necessary for us to study biocide/inhibitor effect on SRB on carbon steel corrosion.

This study may provide theoretical information for the application of oil-cell-free fermentation broth inhibiting carbon steel corrosion in oil industrial environment. Moreover, rhamnolipid, a biosurfactant which is biodegradable, also could inhibit the increasing of SRB. The results presented here 

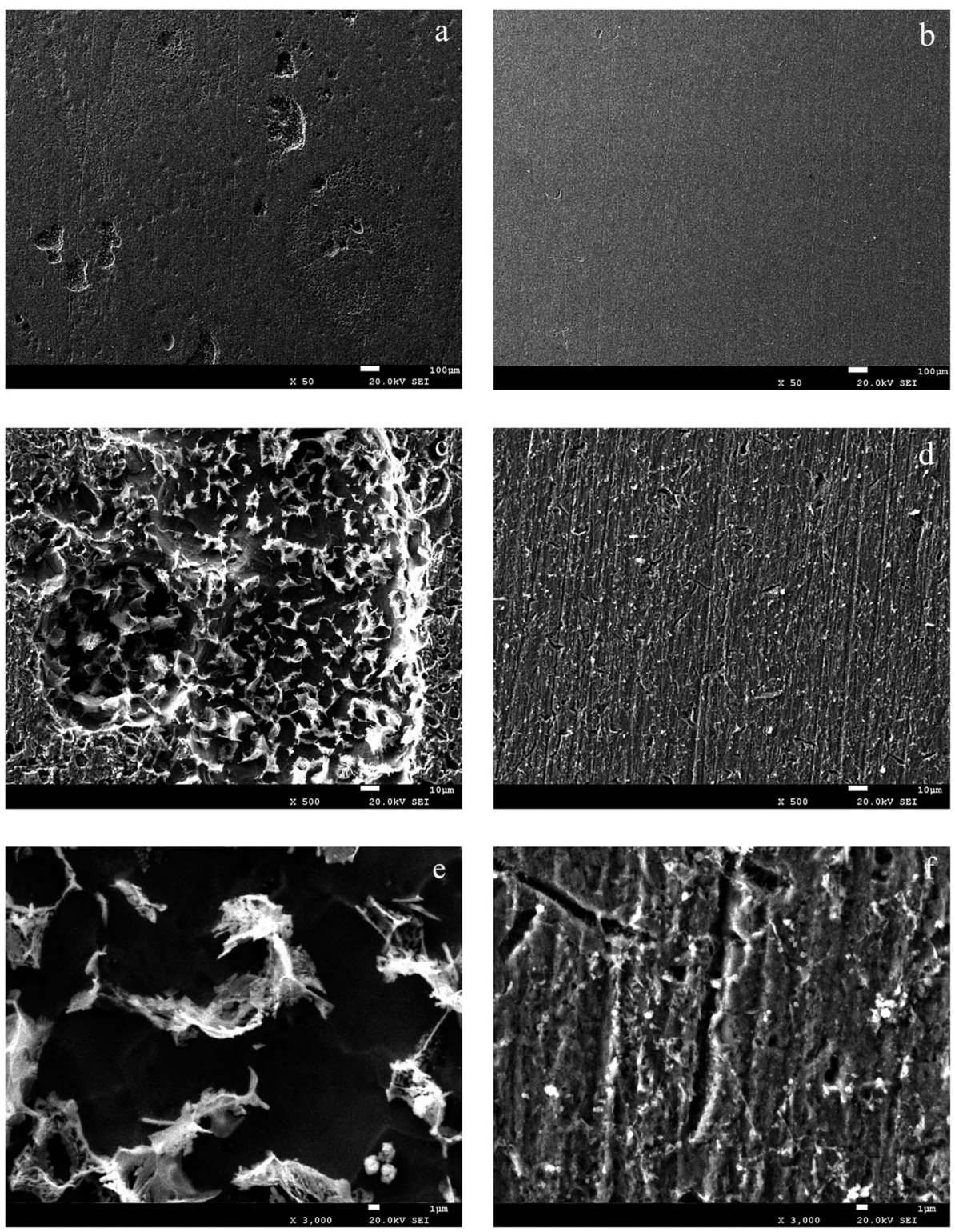

Fig. 14 SEM images of the carbon steel surfaces after corrosion products were removed: (a), (c) and (e) (sterile deionised water); (b), (d) and (f) (oil-cell-free fermentation broth).

Table 7 The results of antibacterial property test

\begin{tabular}{lllllll}
\hline $\begin{array}{l}\text { Bacteria } \\
\text { type }\end{array}$ & $\begin{array}{l}0 \mu \mathrm{g} \\
\mathrm{mL}^{-1}\end{array}$ & $\begin{array}{l}32 \mu \mathrm{g} \\
\mathrm{mL}^{-1}\end{array}$ & $\begin{array}{l}96 \mu \mathrm{g} \\
\mathrm{mL}^{-1}\end{array}$ & $\begin{array}{l}160 \mu \mathrm{g} \\
\mathrm{mL}^{-1}\end{array}$ & $\begin{array}{l}320 \mu \mathrm{g} \\
\mathrm{mL}^{-1}\end{array}$ & $\begin{array}{l}640 \mu \mathrm{g} \\
\mathrm{mL}^{-1}\end{array}$ \\
\hline SRB & 2750 & 110 & 0.6 & 25 & 70 & 275 \\
TGB & 42 & 32 & 22 & 43 & 37 & 44
\end{tabular}

could provide useful information for MIC, and more experiments should be performed to find out a useful and environmental biocide/inhibitor against corrosion.

\section{Conclusions}

Firstly, Pseudomonas sp. SWP-4 caused a weak corrosion behavior on the carbon steel with a corrosion rate of $0.0137 \mathrm{~mm}$ per year.
The approaching to neutral $\mathrm{pH}$ of the medium may contribute to the passive film, resist to the aggressiveness of the medium and then the surface kept in a good protection. EDS approved that Pseudomonas sp. SWP-4 excluded oxygen via respiration compared to corrosion products of carbon steels immersed in the MSM. Electrochemical results (Tafel plots and EIS measurements) showed that during the exponential phase of bacteria growth, Pseudomonas sp. SWP-4 consumed the dissolved oxygen and adsorbed mineral salts and the changeable characteristic of medium accelerated the corrosion rate of carbon steel. From the stationary phase, electrochemical results indicated that fermentation broth of Pseudomonas sp. SWP-4 appeared to without the electrochemical corrosive property. Secondly, it proved that oil-cell-free fermentation broth of Pseudomonas sp. SWP-4 could inhibit the corrosion, and the corrosion rate with 
the bacterium was $0.0059 \mathrm{~mm}$ per year while that in sterile water was $0.0377 \mathrm{~mm}$ per year, which was in agreement with the theory that biosurfactant could act as a barrier to oxygen. Furthermore, SEM showed a patchy distribution over the carbon steel surface. While the oil-cell-free fermentation broth inhibited the corrosion activity of carbon steel and inhibited the increasing of SRB. This could be a good suggestion to make Pseudomonas sp. SWP-4 used widely in oil fields.

\section{Acknowledgements}

This work was financially supported by the Open Projects of Key Laboratory of Oil \& Gas Applied Chemistry of Sichuan Province, Southwest Petroleum University, PR China (YQKF201406). Open Projects of Key Laboratory of Development and Application of Rural Renewable Energy, Ministry of Agriculture, PR China. (2015004)

\section{References}

1 E. J. Gudiña, J. F. Pereira, L. R. Rodrigues, J. A. Coutinho and J. A. Teixeira, Int. Biodeterior. Biodegrad., 2012, 68, 56-64.

2 N. Parmar, A. Singh and O. Ward, Biotech in Enhanced Petroleum Oil Recovery, Springer Group Publisher, 2014, pp. 239-245.

3 W. J. Xia, Z. B. Luo, H. P. Dong, L. Yu, Q. F. Cui and Y. Q. Bi, Appl. Biochem. Biotechnol., 2012, 166, 1148-1166.

4 N. Khondee, S. Tathong, O. Pinyakong, R. Müller, S. Soonglerdsongpha, C. Ruangchainikom, C. Tongcumpou and E. Luepromchai, Biochem. Eng. J., 2015, 93, 47-54.

5 C. Zou, M. Wang, Y. Xing, G. Lan, T. Ge, X. Yan and T. Gu, Biochem. Eng. J., 2014, 90, 49-58.

6 R. Pasumarthi, S. Chandrasekaran and S. Mutnuri, Mar. Pollut. Bull., 2013, 76, 276-282.

7 X. Zhang, D. Xu, C. Zhu, T. Lundaa and K. E. Scherr, Chem. Eng. J., 2012, 209, 138-146.

8 M. J. Johnson and F. Jarvis, J. Am. Chem. Soc., 1949, 71, 41244126.

9 G. Lan, Q. Fan, Y. Liu, C. Chen, G. Li, Y. Liu and X. Yin, Biochem. Eng. J., 2015, 101, 44-54.

10 G. Lan, Q. Fan, Y. Liu, Y. Liu, Y. Liu, X. Yin and M. Luo, Biochem. Eng. J., 2015, 103, 219-226.

11 D. C. White, M. J. Franklin and H. S. Isaacs, Corros. Sci., 1991, 32, 945-952.

12 E. Hamzah, M. F. Hussain, Z. Ibrahim and A. Abaolahi, Arabian J. Sci. Eng., 2014, 39, 6863-6870.

13 P. Esparza, J. Morales, S. González, R. Salvarezza and M. P. Arévalo, Biofouling, 1993, 34, 129-139.

14 M. Moradi, Z. Song, L. Yang, J. Jiang and J. He, Corros. Sci., 2014, 84, 103-112.

15 S. Kjelleberg, A. Pedersen and M. Hermansson, J. Microbiol. Methods, 1988, 8, 191-198.

16 M. Vazquez, J. P. Busalmen and S. R. de Sanchez, Electrochim. Acta, 2002, 47, 1857-1865.
17 I. B. Beech, V. Zinkevich, L. Hanjangsit, R. Gubner and R. Avci, Biofouling, 2000, 15, 3-12.

18 L. Hanjagsit, I. B. Beech, M. Kalaji, A. L. Neal and V. Zinkevich, Microbiology, 1999, 145, 1491-1497.

19 C. C. Gaylarde and I. B. Beech, Int. Biodeterior., 1991, 27, 95107.

20 I. B. Beech, R. Gubner, V. Zinkevich, L. Hanjangsit and R. Avci, Biofouling, 2000, 16, 93-104.

21 N. O. San, H. Nazir and G. Donmez, Corros. Sci., 2014, 79, 177-183.

22 L. C. Xu, K. Y. Chan and H. H. P. Fang, Environ. Sci. Technol., 2002, 36, 1720-1727.

23 S. J. Yuan, A. M. F. Choong and S. O. Pehkonen, Corros. Sci., 2007, 49, 4352-4385.

24 C. Dagbert, T. Meylheuc and M. N. Bellon-Fontaine, Electrochim. Acta, 2006, 51, 5221-5227.

25 T. Meylheuc, C. Dagbert and M. N. Bellon-Fontaine, Electrochim. Acta, 2008, 54, 35-40.

26 F. Liu, J. Zhang, C. Sun, Z. Yu and B. Hou, Corros. Sci., 2014, 83, 375-381.

27 P. J. Antony, R. K. S. Raman, R. Raman and P. Kumar, Corros. Sci., 2010, 52, 1404-1412.

28 D. Cetin and M. L. Aksu, Corros. Sci., 2009, 51, 1584-1588.

29 B. W. A. Sherar, I. M. Power, P. G. Keech, S. Mitlin and G. Southam, Corros. Sci., 2011, 53, 955-960.

30 L. Magalhães and M. Nitschke, Food Control, 2013, 29, 138142.

31 H. Hajfarajollah, S. Mehvari, M. Habibian, B. Mokhtarani and K. A. Noghabi, RSC Adv., 2015, 5, 33089-33097.

32 P. Bharali, J. P. Saikia, A. Ray and B. K. Konwar, Colloids Surf., 2013, 103, 502-509.

33 T. Meylheuc, M. Renault and M. N. Bellon-Fontaine, Int. J. Food Microbiol., 2006, 109, 71-78.

34 T. Lotfabad, F. Shahcheraghi and F. Shooraj, Jundishapur J. Microbiol., 2012, 6, 29-35.

35 M. Dubois, K. A. Gilles, J. K. Hamilton, P. A. Rebers and F. Smith, Anal. Chem., 1956, 28, 350-356.

36 A. Leyva, A. Quintana, M. Sanchez, E. N. Rodriguez, J. Cremata and J. C. Sanchez, Biologicals, 2008, 36, 134-141.

37 M. Benincasa, J. Contiero, M. A. Manresa and I. O. Moraes, J. Food Eng., 2002, 54, 283-288.

38 D. Cetin, S. Bilgiç, S. Dönmez and G. Dönmez, Mater. Corros., 2007, 58, 841-847.

39 J. T. Walker and C. W. Keevil, Int. Biodeterior. Biodegrad., 1994, 33, 223-236.

40 S. O. Pehkonen, X. H. Zhang, N. Kocherginsky and G. A. Ellis, Corros. Sci., 2002, 44, 2507-2528.

41 W. K. Teo, Y. Feng, K. S. Siow and A. K. Hsieh, Corros. Sci., 1996, 38, 387-395.

42 H. A. Videla, Manual de Biocorrosion, CRC Press, 1996.

43 S. Bayoudh, A. Othmane, L. Ponsonnet and H. Ben Ouada, Colloids Surf., A, 2008, 318, 291-300.

44 Y. Yin, S. Cheng, S. Chen, J. Tian, T. Liu and X. Chang, Mater. Sci. Eng., 2009, 29, 756-760. 